\title{
Inflammatory response to a marathon run in amateur athletes
}

\author{
Anna Maria Kaleta-Duss ${ }^{1} \oplus$, Zuzanna Lewicka-Potocka ${ }^{2,3} \oplus^{\oplus}$, \\ Alicja Dąbrowska-Kugacka² ${ }^{\circledR}$, Grzegorz Raczak² ${ }^{\circledR}$, Anna Siekierzycka4® \\ Marcin Woźniak ${ }^{4,5} \oplus$, Leszek Kalinowski ${ }^{\circledR}$, Ewa Katarzyna Lewicka² ${ }^{\circledR}$
}

\author{
${ }^{1}$ Institute of Radiology, Cantonal Hospital of Aargau, Tellstrasse 25, CH-5001 Aarau, Switzerland \\ ${ }^{2}$ Department of Cardiology and Electrotherapy, Medical University of Gdańsk \\ ${ }^{3}$ First Department of Cardiology, Medical University of Gdańsk, Poland \\ ${ }^{4}$ Department of Medical Laboratory Diagnostics - Biobank BBMRI.pl, Medical University of Gdańsk, Poland \\ ${ }^{5}$ Beckman Institute for Advanced Science and Technology, Urbana, IL, USA
}

\begin{abstract}
Background: While moderate physical exercise has positive effects on the cardiovascular system, the data regarding intensive endurance sports is biased with studies suggesting that the inflammatory response to strenuous exercise may act proarrhythmogenic. In amateurs, the effects of intensive endurance exercise on the cardiovascular system have not been studied. Analysis of the effects of a marathon on the kinetics of inflammatory biomarkers may bring new insights into this issue. Material and methods: We studied the effect of a marathon on the kinetics of inflammatory biomarkers: Endothelin-1 (ET-1), Pentraxin-3 (PTX-3), Neopterin and Interleukin-6 (IL-6) in the population of 35 amateur male marathoners. The study was divided into 3 stages: two weeks prior to the marathon (S1), at the finish line (S2) and two weeks after (S3). Blood analyses for biomarkers were performed at each stage. Results: The concentrations of ET-1 ( $3.20 \pm 0.90 \mathrm{vs.} 1.30 \pm 0.34 \mathrm{pg} / \mathrm{ml}, \mathrm{p}<0,001)$, PTX-3 (441.09 \pm 295.64 vs. $279.99 \pm 125.68 \mathrm{pg} / \mathrm{ml}, \mathrm{p}<0,001)$, Neopterin $(9.97 \pm 2.17$ vs. $8.36 \pm 2.68 \mathrm{nmol} / \mathrm{l}, \mathrm{p}<0,05)$ and IL- $6(32.5$ \pm 13.90 vs. $0.97 \pm 0.77 \mathrm{pg} / \mathrm{ml}, \mathrm{p}<0,001$ ) were significantly higher at S2 compared to S1. Conclusions: Running a marathon causes an acute rise in concentrations of inflammatory biomarkers. Further research is needed on the long-term effects of intensive endurance exercise on the cardiovascular system.
\end{abstract}

Keywords: neopterin $\cdot$ endothelin-1 $\cdot$ pentraxin-3 $\cdot$ marathon $\cdot$ amateur runners

\section{Citation}

Kaleta-Duss AM, Lewicka-Potocka Z, Dąbrowska-Kugacka A, Raczak G, Siekierzycka A, Woźniak M, Kalinowski L, Lewicka EK. Eur J TransI Clin Med. 2021;4(1):43-49.

DOI: $10.31373 /$ ejtcm/136659

Corresponding author:

Ewa Lewicka, Department of Cardiology and Electrotherapy, Medical University of Gdańsk, Poland e-mail: elew@gumed.edu.pl

Funding: No external funds

Available online: www.ejtcm.gumed.edu.pl

Copyright ${ }^{\circledR}$ Medical University of Gdańsk

This is Open Access article distributed under the terms of the Creative Commons Attribution-ShareAlike 4.0 International.

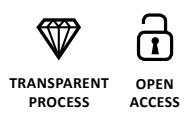




\section{Introduction}

Statistics reveal a trend of increasing participation in mass endurance sports events, with the runners older and slower than ever before [1], which means that the number of amateur runners has increased. Amateur runners constitute a heterogeneous group in terms of fitness level, training regimen, medical history and cardiovascular risk factors. Moreover, the definition of an "amateur athlete" is not precise. The American Heart Association distinguishes elite, competitive and recreational athletes. The first and the second groups train with high intensity in organized teams with an emphasis on competition and performance, whereas the latter engage in sports activity for pleasure and in their spare time.

Regular exercise reduces the cardiovascular risk and all-cause mortality, with a $20-30 \%$ reduction in cardiovascular adverse events compared with patients who have sedentary lifestyle. The current European Society of Cardiology guidelines recommend a minimum of 150 min of exercise of moderate-intensity over 5 days or $75 \mathrm{~min}$ of vigorous exercise over 3 days per week for a healthy adult [2].

Although the benefits of regular moderate intensity exercise remain indisputable, there is a concern that the long duration high-intensity endurance sports may elicit negative effects on the heart by triggering the structural, functional and electrical remodeling, hence increasing the risk of arrhythmias. One of the postulated mechanisms is the inflammatory response following an intensive endurance exercise [3]. Sorokin et al. in their review showed that endurance-trained athletes are at increased risk of developing atrial fibrillation with the possible mechanisms being increased parasympathetic tone, increased atrial size and increased inflammatory reaction [4]. There are also reports that high-intensity leisure-time physical activity by stimulating the inflammatory reaction may contribute to the development of atherosclerosis in the long run [5].

For over 50 years, the utility of various biomarkers in the diagnosis of cardiovascular diseases was analyzed [6], yet their implications still remain not fully understood. Many novel biomarkers were recently discovered including inflammatory biomarkers such as pentraxin-3 (PTX-3) and neopterin. However, there is a lack of data about amateur athletes as to whether such sport activities are associated with the activation of an inflammatory reaction. The aim of this stu dy was to investigate the effect of running a marathon on the inflammatory response in the group of male amateur runners.

\section{Material and Methods}

The study was carried out on a group of 40 male amateur marathoners, who competed in and finished the 2nd PZU Marathon in Gdańsk, Poland. The participation in the study was voluntary. Enrolment into the study was completed via invitations sent to sports clubs. Each participant signed a written consent form prior to enrolment. The study protocol was approved by Independent Bioethics Committee for Scientific Research at Medical University of Gdańsk (No. NKBBN 104/2016). Information about health and training conditions was gathered via structured interviews. Exclusion criteria were: history of past or chronic illness/es. After the finishing the marathon run, we asked the participants to suspend high-intensity training as well as participation in any upcoming competitions. The characteristics of a study group were described previously [7].

We divided the study into three stages. Blood samples from the cubital vein were collected at each stage. Stage 1 was carried out 2 weeks before the run, Stage 2 directly after finishing the run on the finish line and Stage 3 took place 2 weeks after the marathon. Fasting blood samples at Stage 1 and Stage 3 were collected at the cardiology department. Serum was prepared immediately after collection by centrifugation at 2000 $\mathrm{rpm}$ at room temperature for 12 minutes and then stored in $-80^{\circ} \mathrm{C}$ for the further analysis [7].

Samples from each stage were analyzed in terms of the amount of leukocytes, neutrocytes, lymphocytes, monocytes, eosinophils, basophils, immature granulocytes and the concentration of fibrinogen and creatine kinase. Biochemical parameters were analyzed using Architec c8000 (Abbott). Endothelin-1 (ET-1) concentration was measured using a solid phase sandwich Quantikine ELISA (R\&D Systems) with sensitivity of $0.207 \mathrm{pg} / \mathrm{ml}$ and detection range from 0.39 to $25 \mathrm{pg} /$ $\mathrm{ml}$. PTX-3 concentration was measured using a solid phase sandwich ELISA Human Pentraxin 3/TSG-14 DuoSet (R\&D Systems) with detection range from 218 to $14000 \mathrm{pg} / \mathrm{ml}$. Neopterin concentration was measured using a solid phase competition ELISA (Demeditec Diagnostics) with sensitivity of $0.7 \mathrm{nmol} / \mathrm{l}$ and detection range from 1.35 to $111 \mathrm{nmol} / \mathrm{I}$. Interleukin 6 (IL-6) concentration was measured using a solid phase sandwich Quantikine ELISA (R\&D Systems) with a sensitivity of $0.7 \mathrm{pg} / \mathrm{ml}$ and detection range from 3.1 to $300 \mathrm{pg} / \mathrm{ml}$.

Continuous variables were expressed as means \pm standard deviation (SD). Before the statistical analyses, Shapiro-Wilk test was used to test the normal distribution of variables. Analysis of variance (ANOVA) for repeated measures was used to test statistical differences between groups of variables. Post-hoc analysis 
was performed with a Tukey's test. For the variables analyzed at two stages only, the t-test for dependent variables was used. The data was analyzed using Statistica 12 software (StatSoft). A p value $<0.05$ was considered statistically significant [7].

\section{Results}

\section{Study group}

The characteristics of the studied group are presented in Table 1 [7].

\section{Biochemical analysis}

The results of the analysis of white blood cells counts fibrinogen and creatine kinase concentrations are presented in Table 2.

Mean leukocyte count at Stage 1 was $5.8 \mathrm{G} / \mathrm{l}$. At Stage 2 it was $16.5 \mathrm{G} / \mathrm{l}$ and it differed significantly from the results at Stage 1 and Stage 3 . There was no significant difference between leukocyte count at
Table 1. Characteristics of the studied group

\begin{tabular}{|c|c|}
\hline Demographics & $\begin{array}{c}\text { Amateur runners } \\
(\mathbf{N}=35)\end{array}$ \\
\hline Age [years] & $39 \pm 8$ \\
\hline Gender & 35 males (100\%) \\
\hline BMI [kg/m2] & $25 \pm 2$ \\
\hline Ethnicity & 35 Caucasian (100\%) \\
\hline Smokers/non-smokers & 35 non-smokers (100\%) \\
\hline \multicolumn{2}{|c|}{ Training intensity } \\
\hline kilometers run/week & $234 \pm 25$ \\
\hline Marathon finish time [min] & $54.5 \pm 18.6$ \\
\hline
\end{tabular}

Table 2. Biochemical analysis of blood samples collected 2 weeks before the marathon (S1), at the finish line (S2) and 2 weeks after the marathon (S3)

\begin{tabular}{|c|c|c|c|c|c|c|c|c|}
\hline \multirow{2}{*}{ Parameter } & \multirow{2}{*}{$\begin{array}{c}\text { Laboratory } \\
\text { norms }\end{array}$} & S1 & S2 & S3 & ANOVA & \multicolumn{3}{|c|}{ Post-hoc P value } \\
\hline & & & Mean \pm SD & & P value & $\begin{array}{c}\text { S1 } \\
\text { vs. S2 }\end{array}$ & $\begin{array}{c}\text { S2 } \\
\text { vs. S3 }\end{array}$ & $\begin{array}{c}\text { S1 } \\
\text { vs. S3 }\end{array}$ \\
\hline Leukocytes [G/I] & $4.0-10.0$ & $5.8 \pm 1.2$ & $16.5 \pm 3.5$ & $6.0 \pm 1.8$ & $<0.001$ & $<0.001$ & $<0.001$ & 1.0 \\
\hline Neutrocytes [G/I] & $2.0-7.0$ & $3.2 \pm 0.8$ & $13.9 \pm 3.1$ & $3.4 \pm 1.5$ & $<0.001$ & $<0.001$ & $<0.001$ & 0.95 \\
\hline Lymphocytes [G/I] & $1.0-3.0$ & $1.9 \pm 0.5$ & $1.4 \pm 0.6$ & $2.1 \pm 1.1$ & $<0.001$ & 0.007 & $<0.001$ & 0.67 \\
\hline Monocytes [G/I] & $0.2-1.0$ & $0.5 \pm 0.2$ & $1.1 \pm 0.4$ & $0.6 \pm 0.2$ & $<0.001$ & $<0.001$ & $<0.001$ & 1.0 \\
\hline Eosinophils [G/I] & $0.02-0.5$ & $0.2 \pm 0.1$ & $0.0 \pm 0.0$ & $0.2 \pm 0.1$ & $<0.001$ & $<0.001$ & $<0.001$ & 0.98 \\
\hline Basophils [G/I] & $0.0-0.1$ & $0.0 \pm 0.0$ & $0.1 \pm 0.0$ & $0.0 \pm 0.0$ & $<0.001$ & $<0.001$ & $<0.001$ & 0.92 \\
\hline $\begin{array}{c}\text { Immature } \\
\text { granulocytes }[\mathrm{G} / \mathrm{I}]\end{array}$ & $0.00-0.03$ & $0.0 \pm 0.0$ & $0.1 \pm 0.0$ & $0.0 \pm 0.0$ & $<0.001$ & $<0.001$ & $<0.001$ & 0.99 \\
\hline Fibrinogen $[\mathrm{g} / \mathrm{l}]$ & $1.8-3.5$ & $2.7 \pm 0.4$ & $3.0 \pm 0.5$ & $2.5 \pm 0.4$ & $<0.001$ & 0.014 & $<0.001$ & 0.08 \\
\hline $\begin{array}{c}\text { Creatine kinase } \\
{[\mathrm{U} / \mathrm{L}]}\end{array}$ & $30-200$ & $\begin{array}{l}148 \pm \\
76.3\end{array}$ & $411 \pm 170$ & $208 \pm 135$ & $<0.001$ & $<0.001$ & $<0.001$ & 0.09 \\
\hline
\end{tabular}


Stage 1 and Stage 3. The same trend was observed for neutrocytes, lymphocytes, monocytes, eosinophils, basophils and immature granulocytes, as well as for fibrinogen and creatine kinase concentrations. The concentration of creatine kinase at Stage 2 was significantly higher compared to Stage 1 and Stage 3.

\section{Biomarkers}

Table 3 shows the concentrations of the analyzed biomarkers.

The mean concentration of ET-1 was the highest at Stage $2(3.2 \pm 0.9 \mathrm{pg} / \mathrm{ml})$ and it differed significantly from both Stage 1 and Stage 3. Neopterin showed the same trend. PTX-3 concentrations differed significantly between all the stages, with the highest concentration at Stage 2 and the lowest at Stage 3. The concentration of IL- 6 was significantly higher at Stage 2 compared to Stage 1 and exceeded the norm many times (Norm: lower or equal to $1.8 \mathrm{pg} / \mathrm{ml}$ ). At S3 the mean concentrations of IL- 6 were undetectable.

\section{Discussion}

In our study, we found that running a marathon increased the inflammatory response in amateur runners. This was probably due to skeletal muscle damage, as inflammatory biomarkers were normalizing 2 weeks after the run. To our knowledge, this is the first study to demonstrate the impact of a bout of intense exercise on the inflammatory response in male amateur marathoners, assessed on the basis of changes in PTX-3 and neopterin concentrations.
In our study group, increased concentrations of creatine kinase at Stage 2 suggest exercise-induced muscle damage. This was accompanied by a significant increase in concentrations of all the studied biomarkers, compared with Stage 1 and Stage 3. At Stage 2 significant leukocytosis with an increase in all leukocyte-fractions was also observed. Kosowski et al. investigated cardiovascular stress biomarkers in middle-aged non-athlete marathon runners. Blood samples were collected (before, just after and 7 days after the marathon) and analyzed for endothelin-1, troponin I and $\mathrm{N}$-terminal pro B-type natriuretic peptide concentrations. The authors concluded that the marathon was associated with a significant increase in cardiovascular stress biomarkers but the profile of these changes did not suggest irreversible myocardial damage [8].

It has been suggested that completing a marathon has similar physiological sequelae to the acute-phase response: neutrophil leucocytosis, increased creatine kinase activity, a rise in C-reactive protein and fibrinogen levels and an increase in plasma cortisol concentration [9]. On the other hand, significant increases of the creatine kinase concentration and elevation of inflammatory markers have been observed after prolonged cardiopulmonary resuscitation [10] or direct current cardioversion [11].

Endothelin-1, which is released by leukocytes, macrophages and fibroblasts [12], is not only a potent vasoconstrictor of the smooth muscle cells but it also has a pro-inflammatory effect $[13,14]$. Its expression is increased in response to cytokines, reactive oxygen species, angiotensin II and thrombin [15]. ET-1 has been shown to stimulate monocytes to produce interleukin-8 (IL-8) and monocyte chemoattractant

Table 3. Concentrations of cardiac injury and overload biomarkers: 2 weeks before the marathon (S1), at the finish line (S2) and 2 weeks after the marathon (S3)

\begin{tabular}{|c|c|c|c|c|c|c|c|}
\hline \multirow[b]{2}{*}{ Parameter } & S1 & $\mathbf{S 2}$ & S3 & ANOVA & \multicolumn{3}{|c|}{ Post-hoc P value } \\
\hline & \multicolumn{3}{|c|}{ Mean \pm SD } & P value & $\begin{array}{c}\text { S1 } \\
\text { vs. S2 }\end{array}$ & $\begin{array}{c}\text { S2 } \\
\text { vs. S3 }\end{array}$ & $\begin{array}{c}\text { S1 } \\
\text { vs. S3 }\end{array}$ \\
\hline Endothelin-1 [pg/ml] & $1.30 \pm 0.34$ & $3.20 \pm 0.90$ & $1.20 \pm 0.26$ & $<0.001$ & $<0.001$ & $<0.001$ & 1.0 \\
\hline Pentraxin-3 [pg/ml] & $\begin{array}{c}279.99 \pm \\
125.68\end{array}$ & $\begin{array}{c}441.09 \pm \\
295.64\end{array}$ & $\begin{array}{c}165.34 \pm \\
70.79\end{array}$ & $<0.001$ & $<0.001$ & $<0.001$ & 0.95 \\
\hline Neopterin $[\mathrm{nmol} / \mathrm{l}]$ & $8.36 \pm 2.68$ & $9.97 \pm 2.17$ & $7.82 \pm 1.94$ & $<0.001$ & 0.007 & $<0.001$ & 0.67 \\
\hline IL-6 [pg/ml] & $0.97 \pm 0.77$ & $32.5 \pm 13.90$ & ND & $<0.001$ & $<0.001$ & $<0.001$ & 1.0 \\
\hline
\end{tabular}

Interleukin 6 (IL-6), not detectable (ND) 
protein-1 (MCP-1)[16], and also acts as a mast cell activator resulting in the release of inflammatory cytokines such as tumor necrosis factor alpha (TNF-alpha) and IL-6 [17]. A study of mice showed that intensive endurance exercise increases the occurrence of atrial fibrillation in a mechanism of inflammation and atrial fibrosis with the involvement of a soluble TNF-alpha signaling pathway [18]. More than a 33-fold increase in the mean concentration of IL-6 at S2 compared to the baseline value is consistent with the observations of Pinho et al. [19] (a group of Ironman race participants) and Schobersberger et al. [15] (participants of an ultramarathon). Intensive physical exercise causes an increase in oxygen consumption and induces oxidative stress due to free radical production, which in turn stimulates cytokine production from various cell types and upregulates the inflammatory cascade [20-21].

Neopterin is a biomarker of the cellular immune response released by activated macrophages and dendritic cells upon activation with gamma-interferon and acts as a modulator and mediator in inflammatory and infectious processes [22]. A significant increase in the post-run concentration of neopterin is consistent with the observations published by Schobersberger et al. [23] and Sprenger et al. [24] who examined well-trained runners after running $20 \mathrm{~km}$ in 2 hours. The pentraxins superfamily comprises of short and long pentraxins. PTX-3 is a member of long pentraxin group and is believed to play a regulatory role in innate immunity, sterile and non-sterile inflammation, tissue repair, and cancer [25]. PTX-3 is an acute phase protein, produced locally by monocytes, endothelial cells and fibroblasts in response to pro-inflammatory signals like interleukin 1 beta or TNF alpha. The major source of PTX-3 are vascular endothelial cells [26]. Increased plasma levels of PTX-3 were found in patients with acute myocardial infarction, heart failure, atherosclerosis and after cardiac arrest. Salio et al. indicated that PTX-3 plays a protective role against myocardial ischemia in their study on a mouse model of myocardial infarction. PTX3-deficient mice showed exacerbated cardiac damage with greater no-reflow area, increased neutrophil aggregation, decreased number of capillaries and increased number of apoptotic cardiomyocytes [27].

The influence of intense endurance exercise on plasma concentrations of PTX-3 in humans has not yet been extensively studied. Miyaki et al. measured plasma PTX-3 concentrations in young male endurance runners and sedentary controls and found higher concentrations in the first group as a result of a postulated training-induced cardioprotection [28]. In contrast, Suzuki et al. showed a hypertrophic response and left ventricular systolic dysfunction as a consequence of increased afterload in a mouse model of transverse aortic constriction. Transverse aortic constriction (TAC) is one of the most common surgical models of pressure overload-induced cardiac hypertrophy and heart failure. In the TAC model, a permanent constriction is placed around the transverse aorta, limiting left ventricular outflow and thereby creating pressure overload in the left ventricle. Echocardiography indicated that PTX-3 overexpression promoted tissue remodelling, left ventricular systolic dysfunction and myocardial fibrosis, while these responses were suppressed in PTX3-deficient mice [29].

Two weeks after the marathon, white blood cell counts, creatine kinase and fibrinogen levels, as well as ET-1 and neopterin concentrations returned to baseline, and PTX-3 level fell below the Stage 1 value. The concentration of IL-6 at S3 was undetectable. We explain this by the lack of intensive training or participation in any sporting events between S2 and S3 compared to the pre-marathon preparation period according to the study protocol. This trend suggests that a marathon run does not cause a prolonged inflammatory response.

On the other hand, numerous studies have reported that health benefits from extreme forms of physical activity such as ultra-endurance sports, are attenuated in an inverted J-curve dose-response model, with increased risk of adverse ventricular remodeling, fibrosis and arrhythmias. La Gerche emphasizes the phenomenon of cardiac overtraining in the potential mechanism of arrhythmogenesis in endurance athletes, in which a chronic adverse cardiac remodeling depicts an imbalance between the exercise-induced injury and an insufficient period of regeneration [30-31].

Kwaśniewska et al. observed the population of physically active men for over 25 years and reported that the most favourable effect against atherosclerosis was associated with energy expenditure between 2050 and $3840 \mathrm{kcal} /$ week. Regular and very high physical activity was accompanied by the deterioration of the examined indicators of atherosclerosis (increased calcification of the coronary arteries and intima-media thickness). The authors postulated that intense physical activity in free time may be associated with the intensification of low-grade inflammation and thus has a pro-atherosclerotic effect [5].

Currently, there is little data available regarding the long-term effects of intense endurance activity on the inflammatory response. However, a prospective, long-term study of at least 130 marathon runners is currently underway by Schoenfeld et al. [32] and may provide important information on this topic. The aim of this study is to assess the physiological response of the cardiovascular system and potential abnormalities after 10 years of long-term vigorous endurance exercise. 
The main limitation of our study is the lack of a long-time observation. The biomarker kinetics were not monitored in the time interval between S2 and S3. Secondly, the study was conducted on a relatively small group of male participants only. Finally, we did not include echocardiographic imaging, however this was not the purpose of this part of the study.

Conclusions

Our study appears to be the first to investigate the changes in PTX-3 and neopterin concentrations in amateur athletes. We demonstrated that male amateur marathon runners follow similar trends in inflammation biomarker kinetics as in Ironmen, ultramarathoners and elite athletes. Intensive endurance exercise causes an acute transient rise in the concentrations of inflammatory biomarkers in amateur marathon runners together with leukocytosis and increased creatine kinase. In the short-term follow-up, the concentrations of all studied parameters normalized, suggesting that the inflammatory cascade is mainly induced by exercise-induced muscular damage. Further research is needed to investigate the long-term effects of recurrent exercise-induced inflammation on the cardiovascular system.

\section{Acknowledgements: None declared.}

Statement of competing interests: None declared.

\section{References}

1. Andersen JJ. The State of Running 2019 / RunRepeat [Internet]. 2021 [cited 2021 May 12]. Available from: https://runrepeat.com/state-of-running

2. Pelliccia A, Sharma S, Gati S, Bäck M, Börjesson M, Caselli S, et al. 2020 ESC Guidelines on sports cardiology and exercise in patients with cardiovascular disease. Eur Heart J [Internet]. 2021 Jan 1;42(1):17-96. Available from: https://doi. org/10.1093/eurhearti/ehaa605

3. La Gerche A, Inder WJ, Roberts TJ, Brosnan MJ, Heidbuchel H, Prior DL. Relationship between Inflammatory Cytokines and Indices of Cardiac Dysfunction following Intense Endurance Exercise. Tauler P, editor. PLoS One [Internet]. 2015 Jun 12;10(6):e0130031. Available from: https://doi.org/10.1371/journal.pone.0130031

4. Sorokin A V., Araujo CGS, Zweibel S, Thompson PD. Atrial fibrillation in endurance-trained athletes. Br J Sports Med [Internet]. 2011 Mar 1;45(3):185-8. Available from: https://doi.org/10.1136/bjsm.2009.057885

5. Kwaśniewska M, Kostka T, Jegier A, Dziankowska-Zaborszczyk E, Leszczyńska J, Rębowska E, et al. Regular physical activity and cardiovascular biomarkers in prevention of atherosclerosis in men: a 25 -year prospective cohort study. BMC Cardiovasc Disord [Internet]. 2016 Dec 5;16(1):65. Available from: http://bmccardiovascdisord.biomedcentral.com/articles/10.1186/s12872-016-0239-x

6. Garg P, Morris P, Fazlanie AL, Vijayan S, Dancso B, Dastidar AG, et al. Cardiac biomarkers of acute coronary syndrome: from history to high-sensitivity cardiac troponin. Intern Emerg Med [Internet]. 2017 Mar 11;12(2):147-55. Available from: http://link.springer.com/10.1007/s11739-017-1612-1

7. Kaleta-Duss AM, Lewicka-Potocka Z, Dąbrowska-Kugacka A, Raczak G, Lewicka E. Myocardial Injury and Overload among Amateur Marathoners as Indicated by Changes in Concentrations of Cardiovascular Biomarkers. Int J Environ Res Public Health [Internet]. 2020 Aug 26;17(17):6191. Available from: https://www.mdpi.com/1660-4601/17/17/6191

8. Kosowski M, Młynarska K, Chmura J, Kustrzycka-Kratochwil D, Sukiennik-Kujawa M, Todd JA, et al. Cardiovascular stress biomarker assessment of middle-aged non-athlete marathon runners. Eur J Prev Cardiol [Internet]. 2019 Feb 6;26(3):318-27. Available from: https://academic.oup.com/eurjpc/article/26/3/318-327/5925631

9. Weight LM, Alexander D, Jacobs P. Strenuous exercise: analogous to the acute-phase response? Clin Sci [Internet]. 1991 Nov 1;81(5):677-83. Available from: https://portlandpress.com/clinsci/article/81/5/677/75458/Strenuous-exercise-analogous-to-the-acutephase

10. Mattana J, Singhal PC. Determinants of Elevated Creatine Kinase Activity and Creatine Kinase MB-Fraction following Cardiopulmonary Resuscitation. Chest [Internet]. 1992 May;101(5):1386-92. Available from: https://linkinghub.elsevier. com/retrieve/pii/S0012369216341472

11. Gajek J, Zyśko D, Mysiak A, Mazurek W. Activation of generalised inflammatory reaction following electrical cardioversion. Kardiol Pol (Polish Hear Journal) [Internet]. 2004;61(9):229-31. Available from: https://journals.viamedica.pl/ kardiologia polska/article/view/81824

12. Gu J, Pinheiro JMB, Yu C-Z, D’andrea M, Muralidharan S, Malik A. Detection of endothelin-like immunoreactivity in epithelium and fibroblasts of the human umbilical cord. Tissue Cell [Internet]. 1991 Jan;23(4):437-44. Available from: https://linkinghub.elsevier.com/retrieve/pii/004081669190002B 
13. Teder P, Noble PW. A Cytokine Reborn? Am J Respir Cell Mol Biol [Internet]. 2000 Jul;23(1):7-10. Available from: http:// www.atsjournals.org/doi/abs/10.1165/ajrcmb.23.1.f192

14. Sessa WC, Kaw S, Hecker M, Vane JR. The biosynthesis of endothelin-1 by human polymorphonuclear leukocytes. Biochem Biophys Res Commun [Internet]. 1991 Jan;174(2):613-8. Available from: https://linkinghub.elsevier.com/retrieve/ pii/0006291X9191461K

15. Kedzierski RM, Yanagisawa M. E $<\mathrm{scp}>$ NDOTHELIN $</ s c p>S<s c p>$ YSTEM $</ s c p>$ : The Double-Edged Sword in Health and Disease. Annu Rev Pharmacol Toxicol [Internet]. 2001 Apr;41(1):851-76. Available from: http://www.annualreviews. org/doi/10.1146/annurev.pharmtox.41.1.851

16. Helset E, Sildnes T, Konopski ZS. Endothelin-1 Stimulates Monocytes in vitro to Release Chemotactic Activity Identified as Interleukin-8 and Monocyte Chemotactic Protein-1. Mediators Inflamm [Internet]. 1994;3(2):155-60. Available from: http://www.hindawi.com/journals/mi/1994/145147/abs/

17. Matsushima H, Yamada N, Matsue H, Shimada S. The effects of endothelin-1 on degranulation, cytokine, and growth factor production by skin-derived mast cells. Eur J Immunol [Internet]. 2004 Jul;34(7):1910-9. Available from: http://doi. wiley.com/10.1002/eji.200424912

18. Lakin R, Polidovitch N, Yang S, Guzman C, Gao X, Wauchop M, et al. Inhibition of soluble TNFa prevents adverse atrial remodeling and atrial arrhythmia susceptibility induced in mice by endurance exercise. J Mol Cell Cardiol [Internet]. 2019 Apr;129:165-73. Available from: https://linkinghub.elsevier.com/retrieve/pii/S0022282818311325

19. Pinho RA, Silva LA, Pinho CA, Scheffer DL, Souza CT, Benetti M, et al. Oxidative Stress and Inflammatory Parameters After an Ironman Race. Clin J Sport Med [Internet]. 2010 Jul;20(4):306-11. Available from: https://journals.Iww. com/00042752-201007000-00010

20. Mastaloudis A, Leonard SW, Traber MG. Oxidative stress in athletes during extreme endurance exercise. Free Radic Biol Med [Internet]. 2001 Oct;31(7):911-22. Available from: https://linkinghub.elsevier.com/retrieve/pii/S0891584901006670

21. Fisher-Wellman K, Bloomer RJ. Acute exercise and oxidative stress: a 30 year history. Dyn Med [Internet]. 2009 Dec 13;8(1):1. Available from: https://dynamic-med.biomedcentral.com/articles/10.1186/1476-5918-8-1

22. Pingle S, Tumane R, Jawade A. Neopterin: Biomarker of cell-mediated immunity and potent usage as biomarker in silicosis and other occupational diseases. Indian J Occup Environ Med [Internet]. 2008;12(3):107. Available from: http://www. ijoem.com/text.asp?2008/12/3/107/44690

23. Schobersberger W, Hobisch-Hagen P, Fries D, Wiedermann F, Rieder-Scharinger J, Villiger B, et al. Increase in Immune Activation, Vascular Endothelial Growth Factor and Erythropoietin after an Ultramarathon Run at Moderate Altitude. Immunobiology [Internet]. 2000 Apr;201(5):611-20. Available from: https://linkinghub.elsevier.com/retrieve/pii/S0171298500800789

24. Sprenger H, Jacobs C, Nain M, Gressner AM, Prinz H, Wesemann W, et al. Enhanced release of cytokines, interleukin-2 receptors, and neopterin after long-distance running. Clin Immunol Immunopathol [Internet]. 1992 May;63(2):188-95. Available from: https://linkinghub.elsevier.com/retrieve/pii/009012299290012D

25. Garlanda C, Bottazzi B, Magrini E, Inforzato A, Mantovani A. PTX3, a Humoral Pattern Recognition Molecule, in Innate Immunity, Tissue Repair, and Cancer. Physiol Rev [Internet]. 2018 Apr 1;98(2):623-39. Available from: https://www.physiology.org/doi/10.1152/physrev.00016.2017

26. Breviario F, D’Aniello EM, Golay J, Peri G, Bottazzi B, Bairoch A, et al. Interleukin-1-inducible genes in endothelial cells. Cloning of a new gene related to C-reactive protein and serum amyloid P component. J Biol Chem [Internet]. 1992 Nov;267(31):22190-7. Available from: https://linkinghub.elsevier.com/retrieve/pii/S0021925818416535

27. Salio M, Chimenti S, De Angelis N, Molla F, Maina V, Nebuloni M, et al. Cardioprotective Function of the Long Pentraxin PTX3 in Acute Myocardial Infarction. Circulation [Internet]. 2008 Feb 26;117(8):1055-64. Available from: https://www. ahajournals.org/doi/10.1161/CIRCULATIONAHA.107.749234

28. Miyaki A, Maeda S, Otsuki T, Ajisaka R. Plasma Pentraxin 3 Concentration Increases in Endurance-Trained Men. Med Sci Sport Exerc [Internet]. 2011 Jan;43(1):12-7. Available from: https://journals.Iww.com/00005768-201101000-00003

29. Suzuki S, Shishido T, Funayama A, Netsu S, Ishino M, Kitahara T, et al. Long Pentraxin PTX3 Exacerbates Pressure Overload-Induced Left Ventricular Dysfunction. Chen X, editor. PLoS One [Internet]. 2013 Jan 23;8(1):e53133. Available from: https://dx.plos.org/10.1371/journal.pone.0053133

30. Gerche A La, Heidbuchel H. Can Intensive Exercise Harm the Heart? Circulation [Internet]. 2014 Sep 16;130(12):9921002. Available from: https://www.ahajournals.org/doi/10.1161/CIRCULATIONAHA.114.008141

31. Heidbuchel H, Prior DL, La Gerche A. Ventricular arrhythmias associated with long-term endurance sports: what is the evidence? Br J Sports Med [Internet]. 2012 Nov;46(Suppl 1):i44-50. Available from: https://bjsm.bmj.com/lookup/ doi/10.1136/bjsports-2012-091162

32. Schoenfeld J, Schindler MJ, Haller B, Holdenrieder S, Nieman DC, Halle M, et al. Prospective long-term follow-up analysis of the cardiovascular system in marathon runners: study design of the Pro-MagIC study. BMJ Open Sport Exerc Med [Internet]. $2020 \mathrm{Jul}$ 19;6(1):e000786. Available from: https://bmjopensem.bmj.com/lookup/doi/10.1136/bmjsem-2020-000786 